\title{
O TABU DO PODER E DA POLÍTICA NOS ESTUDOS ORGANIZACIONAIS
}

\author{
Power and political tabu in \\ organizational studies
}

Envio16.10.08 / Aceite 24.10.08

Sandra Miranda ${ }^{1}$

\section{Resumo}

A ideia generalizada de que as organizações são espaços altamente permeáveis e atreitos ao exercício do poder e da movimentação política e de que muitas das decisões que aí ocorrem não reflectem, necessariamente, os interesses do pretenso bem comum, contrasta com um certo "acanhamento" da parte dos investigadores organizacionais em abordar e estudar o fenómeno. O presente artigo tem como objectivo discutir as principais razões que estão por detrás desta tímida e algo escassa produção teórica e empírica, salientado que ao ignorarmos a inevitabilidade do poder e da política estaremos a omitir uma das mais reveladoras e determinantes peças do puzzle organizacional.

Palavras-chave: Poder; Política; Comportamento Político; Comportamento Organizacional.

\section{Abstract}

The general idea that organizations are wide opened terrain for power strategies and politic influenza bringing hidden agendas upon the table, doesn't match the strangely shyness from the organizational researchers about the phenomena. This article set its goal on the main reasons behind this rare and shy theoretical and empirical production, overcoming that when ignoring the power and politic inevitability, we are hiding one of the most revealing and critical pieces of the organizational puzzle.

Keywords: Diversification Strategies; Organizational Development; Expansion of Business; Shoes Industry; Path.

\footnotetext{
1Phd em Comunicação Social: especialização em Comunicação Organizacional. Equiparada a Professora Adjunta na Escola Superior Comunicação de Lisboa (Instituto Politécnico de Lisboa), Portugal. End.: Campus de Benfica do IPL, CEP 1549-014, Lisboa. E-mail: Smiranda@escs.ipl.pt
} 
O poder e a política são os últimos segredos sujos das organizações modernas (KANTER, 1979, p. 65).

Existem dois tipos de proposições, as minhas e as tuas. As minhas, são propostas para o bem-estar comum que implicam (muito contra a minha vontade) a ascensão de alguns dos meus amigos, ou então (ainda muito mais contra a minha vontade) a minha ascensão. As tuas propostas são intrigas insidiosas promovendo a tua ascensão e a dos teus amigos, que pretendes fazer passar por propostas benéficas para o bem comum (CORNFORD in BURNS, 1962, p. 260).

\section{Introdução}

Apesar de, actualmente, ser mais ou menos pacífica a ideia de que as organizações são arenas políticas (MINTZBERG, 1983) onde se joga o jogo do poder e da política (CROZIER, 1973), a atenção e o interesse que estas temáticas têm concitado em seu redor não é sequer comparável à granjeada e recebida por outras bastante mais populares no âmbito do comportamento organizacional - como é o caso da satisfação, da motivação, da liderança e da cultura organizacional (FARRELL e PETERSON, 1982). A verdade é que durante décadas, parcas foram as pesquisas e os estudos realizados sobre as relações de poder e os comportamentos políticos manifestados pelos actores inseridos em cenários de trabalho. Indubitável é a constatação de os primeiros manuais da disciplina ignorarem por completo estas temáticas, ou então tratarem-nas com ostracismo, de forma simplista, ingénua e incipiente, remetendo-as para umas breves e irrisórias notas laterais (HARDY, 1995; CUNHA et al., 2003).

Esta subvalorização é passível de explicação por duas grandes ordens de razões: por um lado, a lente do paradigma funcionalista e racionalista focou, por demasiado tempo, o estudo das organizações, o que lhe conferiu limitações profundas em termos conceptuais e no desenvolvimento de instrumentos necessários ao estudo destas matérias (ALVESSON, 1984; BRADSHAW-CAMBALL e MURRAY, 1991). Na verdade, o abonamento social da racionalidade e os contributos provenientes de disciplinas como a gestão, a engenharia e a economia, contribuíram para fazer da perspectiva racional o modus operandi dominante em ciência organizacional no século XX.

Aliás, a visão racional e musculada da organização como uma máquina encontra-se profundamente enraizada desde os postulados de Fredrick Taylor até aos de Herbert Simon, James March e Richard Cyert ${ }^{2}$ (famoso grupo de Carnegie), todos eles reduzindo (ou ignorando) os aspectos informais e emocionais do comportamento nas organizações a hard-data - porque racionalmente inexplicáveis - em que o poder era o equivalente ao exercício de autoridade e, em certa medida, sinónimo de competência (MARCH e SIMON, 1958 e 1993; CYERT e MARCH, 1963; PEABODY, 1962).

\footnotetext{
2 Pese embora March e Cyert serem, inicialmente, adeptos fervorosos do racionalismo, em trabalhos posteriores, numa espécie de acto de contrição, identificaram algumas limitações inerentes aos seus estudos. March (1966) ao efectuar uma revisão da literatura sobre o poder concluiu que os estudos efectuados em torno desta temática apenas serviram para realçar e sublinhar a ignorância dos investigadores. Por outro lado, Cyert em parceria com March (1963), ao proporem a teoria comportamental da firma, reconhecem a presença de uma dimensão política na tomada de decisão, muito embora não dêem grande destaque ao papel da comunicação e informação na tomada de decisão, aos processos de formacão de coligações de interesses e aos efeitos da filiação profissional dos intervenientes - elementos, actualmente, indicados como cruciais para compreendermos o processo de tomada de decisão nas organizações, ainda mais quando falamos de decisões estratégicas (PETTIGREW, 1973; NARAYANAN e FAHEY, 1982; MUMBY, 2000).
} 
De alguma forma, deparamo-nos com uma concepção absolutamente naivë do homem organizacional, desprovido de ambições, invejas, malícias e interesses pessoais, trabalhando afincadamente na senda do objectivo comum. Daí que, qualquer comportamento humano polarizado à volta do exercício do poder que escapasse à autoridade formal e se situasse fora dos arranjos organizacionais, era visto como um foco desestabilizador de conflito e política, altamente disfuncional e pernicioso para a organização e para a prossecução dos seus objectivos. Sendo visto como factor de criação de situações negativas para o funcionamento das organizações, via-se nele a origem das greves, sabotagens e acções individuais e colectivas que se corporizavam facilmente em atitudes contestatárias (NORD, 1978).

Um outro factor explicativo da continuada omissão dos aspectos relacionados com o poder e a política, prende-se com a má reputação e a conotação extremamente negativa associada a esses dois termos. Para Crozier (1973) e Kanter (1979), na essência, tudo se resume à presença de um poderoso e preconceituoso tabu moral, claramente ilustrado nas suas palavras: "o tabu do poder está mais enraizado nos homens modernos do que o tabu do sexo" (CROZIER, 1973, p. 214); ou ainda "o poder é a última palavra feia da América, é mais fácil falar com alguém sobre dinheiro e sexo, do que falar sobre poder (KANTER, 1979, p. 65).

Estes conceitos são, amiúde, apontados como exemplos de comportamentos social, ética e moralmente reprováveis, ilegítimos e ilícitos (como é o caso da troca de favores, do "lobbying", da corrupção, da lisonja, das ameaças, da pressão, entre outros) que, em última instância, apenas beneficiam os interesses pessoais do indivíduo ou do grupo envolvido em tais práticas. Este reconhecimento da faceta "feia" e "suja" do poder e da política prolifera nos mais diversos domínios da nossa sociedade, veja-se a título ilustrativo a afirmação proferida por José Saramago, nobel da literatura, ao comentar a actuação do Presidente da República do Brasil: "o tema central da obra $\mathrm{O}$ Homem Duplicado tem semelhanças com a história do presidente Lula. Um certo dia, um homem descobre outro que é totalmente idêntico a ele, mas cuja história de vida é bem distinta. O Lula da Silva que conhecíamos não tomaria uma série de medidas que tomou, mas a história é que o poder corrompe as pessoas" (SARAMAGO, 2004).

Sendo líquido que os contornos e os desafios cada vez menos previsíveis das actuais paisagens competitivas mergulharam as organizações em climas altamente fluidos, ambíguos e atreitos à trama política, e de que uma parte importante das decisões que aí ocorrem espelham, acima de tudo, o poder relativo e a influência exercida por alguns indivíduos e grupos de interesse, em larga medida, na informalidade dos bastidores e de um modo mais ou menos discreto (DRORY e ROMM, 1990), o presente artigo tem como principal objectivo aflorar as razões que estão por detrás duma parca produção teórica e empírica em torno da temática, sublinhando e desmistificando, igualmente, a importância de projectar um olhar clínico pelos "bastidores" das organizações sob pena de estarmos a omitir uma peça chave da engrenagem, da dinâmica e do comportamento organizacional.

\section{Olhar os "bastidores" das organizações}

Pfeffer $(1981 ; 1992)$ ao descrever o que apelidou de ambivalência em relação ao poder em cenários de trabalho aluiu que qualquer cidadão aceita pacificamente a ideia de que os governos são organizações no entanto, o contrário é veementemente negado. Daí que, na esteira de Burns (1961), sempre que se pretende discutir a actividade política interna da organização, absolutamente ninguém se revê na figura de um político - ou agindo como tal com excepção para as práticas e comportamentos que, inusitadamente, são manobrados para salvaguardar e defender os mais elevados interesses da organização 
Apenas nesta óptica se pode aceitar a metáfora da organização política, de outro modo o uso destas palavras ancora-se numa conotação extremamente pejorativa, proferida para especificar ou criticar um comportamento ou um modo particular de acção. Medison et al. (1980) observaram que sempre que os indivíduos eram convidados a descrever incidentes políticos, eles listavam actividades ilegítimas, subversivas e manipuladores. Desta forma, parece justificar-se a afirmação de Gardner (1990, p. 55) segundo a qual, "o poder tem tão má reputação que muito boa gente se convence que não quer nada com ele".

Contudo, muito embora seja aparentemente notório o distanciamento e até repúdio dos actores organizacionais no que diz respeito a estas temáticas, parece-nos que a leitura e a interpretação que delas fazemos não se deve circunscrever ao que anteriormente foi discutido, sob pena de obtermos uma visão simplista, falaciosa e redutora do fenómeno. Para isso, basta projectarmos a nossa atenção na investigação levada a cabo por Gandz e Murray (1980) e logo verificarmos que as respostas obtidas junto dos 428 gestores ilustram e encerram um conjunto de contradições e ambivalências relativamente ao poder e ao comportamento político existente nas organizações, senão vejamos: cerca de $90 \%$ dos inquiridos têm noção de que a política e os comportamentos políticos são uma realidade insofismável nas organizações; 89\% afirmam existir uma relação de causa-efeito entre o sucesso do líder e a posse de competências políticas. Por outro lado, 59\% dos respondentes concordam que a política interfere negativamente na eficácia e eficiência organizacional e quase metade é da opinião de que as organizações deviam livrar-se do factor político.

Idênticas conclusões foram sumariadas por Buchanan e Badham (1999). Ao procurarem aferir o papel do poder e da política em processos de mudança, verificaram que a esmagadora maioria dos respondentes concorda com a ideia de que o líder que não possua competências políticas está irremediavelmente condenado ao insucesso. Afirmação que, de alguma forma, é contradita com os apenas 56\% que aluem positivamente à imagem do gestor como um habilidoso "activista político"3 (BUCHANAN e BADHAM (1999, p. 20). Além disso, 53\% acreditam que a política é o equivalente a gestão danosa e incompetente, logo deveria ser erradicada, ao passo que $46 \%$ dos respondentes a vêem como beneficiando os resultados organizacionais.

Em função do exposto, parece-nos correcto afirmar que os indivíduos estabelecem com esta realidade uma espécie de relação amor-ódio isto é, estão cientes da sua existência e da sua importância, são participantes activos no jogo político (GIOIA e LONGNECKER, 1994) mas, ao mesmo tempo, defendem a sua abolição, já que a entendem como uma actividade pouco transparente onde só alguns são conhecedores das regras do jogo.

Mas esta visão negativa do poder e da política não se esgota no que acabou de ser discutido. Ela encontra-se igualmente, entrincheirada no entendimento e na conceptualização que alguns investigadores (MAYES e ALLEN, 1977; ALLEN et al., 1979; DRORY e ROMM, 1990; GANDZ e MURRAY, 1980; PFEFFER, 1981; FARRELL e PATERSON, 1982; MINTZBERG, 1983; PORTER, ALLEN e ANGLE, 1983; EISENHARDT e BOURGEOIS III, 1988; GIOIA e LONGNECKER, 1994; FERRIS, FEDOR e KING, 1994) têm acerca do fenómeno - espartilhado em acções e manifestações disruptivas, altamente disfuncionais para a organização, senão vejamos: são comportamentos intencionais ou discricionários. Têm acção privilegiada no seio da informalidade - implicando, entre outras coisas, a actuação por detrás do pano; a fuga, o distanciamento ou a conflitualidade relativamente aos objectivos organizacionais. Através das

\footnotetext{
${ }^{3}$ De acordo com Buchanan e Badham (1999), a razão desta ambivalência radica, essencialmente, no termo activista. Ao discutirem com os inquiridos os resultados aferidos no estudo concluíram que este termo tinha uma conotação extremamente forte despoletando significações muito próximas dos comportamentos narcisistas com satisfação dos interesses pessoais.
} 
estruturas informais, os actores organizacionais procuram desenvolver os objectivos e estratégias individuais e grupais que não conseguem almejar no plano das estruturas e das funções inscritas na autoridade hierárquica formal das organizações. E, finalmente, encerram uma dimensão extremamente narcisista e egoísta dos indivíduos, que agem tendo em vista a prossecução e a promoção dos seus interesses pessoais.

Em relação a este último item, importa acautelar algumas erradas generalizações que, acerca dele, podemos fazer. Se tivermos em conta que os interesses individuais têm que, de alguma forma, estar contemplados nos objectivos do todo, poder-se-ía concluir que todos os comportamentos são políticos. Por esta razão, Mayes e Allen (1977) e Drory e Room (1980) propuseram a distinção entre a utilização política (manuseamento de meios e fins não sancionados) e não política do poder, implicando que na utilização política o benefício pessoal está bastante mais vincado do que na utilização não política, "abrangendo um conjunto de acções que, muito embora justificadas em defesa da sobrevivência organizacional, são moralmente repugnantes" (CAVANAGH, MOBERG e VELASQUEZ, 1981, p. 364).

Com uma postura crítica, Farrell e Peterson (1982) afirmam que o desdém pela satisfação dos interesses pessoais encerra alguma hipocrisia uma vez que tanto os valores dominantes, como o american way of live gravitam em torno da bandeira individualismo e da primazia dos interesses próprios. Clegg e Hardy (1996), ao comentarem o estado da arte, lançaram a seguinte provocação: se são apenas os bad boys que fazem uso do poder e manifestam comportamentos políticos, então os good guys utilizam outra coisa qualquer que ainda não foi devidamente identificada e explicada!

\section{Dr. Jekyll ou Mr. Hyde? - a bipolaridade do poder e da política nas organizaçõescompetitiva}

Apesar de estarmos conscientes de que em algumas circunstâncias é válida a afirmação de Lord Acton "o poder corrompe, o poder absoluto corrompe absolutamente" (in FRENCH e BELL JR., 2000, p. 280) e de que a sua manifestação política pode assumir contornos sombrios, podendo estar na origem de graves patologias organizacionais (EISENHARDT e BOURGEOIS, 1988) este juízo de valor deve ser, sob pena de omitirmos uma peça chave do puzzle organizacional, balanceado com o reconhecimento de que estas são dimensões essenciais, naturais e inevitáveis da vida organizacional e não necessariamente disfuncionais, englobando um conjunto de aspectos em relação aos quais podemos aceitar ou rejeitar.

Para isso, é pertinente auscultarmos o seu significado original e verificarmos que a noção política nasce da ideia de que quando os interesses são divergentes, a sociedade deve oferecer meios que ajudem os indivíduos a reconciliarem as suas diferenças através da consulta e da negociação. Já Aristóteles, na Grécia antiga, via a política como uma preciosa ferramenta que fornecia meios para criar a ordem na diversidade enquanto se evitavam formas e regras totalitárias (MORGAN, 1996).

Na sua essência, o poder e a política não são maus nem são bons, é o uso que deles fazemos que vão determinar tais apreciações. Por essa razão, David McClelland identificou as duas faces de poder - a positiva e a negativa. No seu entender, pese embora a conotação negativa adstrita ao conceito de poder, é pelo uso deste que o mundo avança e progride. A faceta negativa do poder diz respeito a uma necessidade primitiva de dominar os outros através da submissão. A versão positiva do poder prende-se com a vontade de iniciar, influenciar e liderar. Na maioria das organizações prevalece a dimensão positiva do poder, facto que foi atestado pelos trabalhos de Patchen (1974) e Roberts (1986). 
Na esteira do que anteriormente foi aduzido, Bugental e Lin (2001) assemelham o fenómeno do poder e da política a uma personalidade bipolar, muito ao jeito de Dr. Jekyl e Mr. Hyde, verificando-se uma oposição entre a acção pensada, reflectida, controlada e responsável e os comportamentos impulsivos, descontrolados e sobranceiros.

Com uma visão eminentemente empresarial, Bader (1991) - CEO, defende que dadas as características das organizações actuais, o poder, o comportamento político, a competição, e o conflito não podem ser vistos como sinistros, problemáticos, com contornos maquiavélicos em que os fins justificam os meios. O comportamento político construtivo contribui activamente para a mudança, progresso, tomada de decisão e alocação de recursos (entre outras coisas), pelo que a sua abolição significaria o secar da fonte da energia criativa (HARDY, 1995). Desta forma, o líder que não possua competências políticas para lidar com esta nova realidade está irremediavelmente condenado ao insucesso, comprometendo os resultados organizacionais.

Assim, parece líquido que os resultados de uma organização estão dependentes do modo como os actores organizacionais se posicionam no campo do poder e da política, facto que constitui razão mais do que suficiente para que os gestores se interessem por estas questões, procurem compreender o seu enredo e se coloquem devidamente no terreno. Se isso não acontecer, os líderes organizacionais correm o risco de usar o poder e a política quando não é necessário e, por isso, violarem normas de comportamento, desperdiçarem recursos, ou subestimarem o grau em que tais mecanismos precisam de ser empregues e falhar a missão de aplicação (PFEFFER, 1981).

Pfeffer (1992, p. 21-22) alerta que não é por evitarmos ou fingirmos desconhecer a realidade social do poder, da influência e da política que ela se dissipa. Muito pelo contrário, essa postura apenas contribui para o agravar do principal problema com o qual as empresas se debatem nos dias que correm:

\footnotetext{
a incapacidade quase treinada ou produzida de qualquer pessoa [...] para desencadear acções e realizar coisas [...] Há política envolvida nas organizações. E a menos e até queiramos entender-nos com o poder e a influência organizacionais, e admitir que as técnicas de realização das coisas são tão importantes como as técnicas de imaginar o que fazer, as nossas organizações atrasar-se-ão cada vez mais.
}

Para Buchanan e Badham (1999, p. 1), se manifestarmos inabilidade para aceitar e compreender a organização como um território eminentemente político, estaremos a ignorar as especificidades da organização pós-moderna. A fluidez, a mudança, a incerteza, a ambiguidade e a descontinuidade que the são inerentes despoletam novas relações de poder onde "os jogadores competem arduamente pelo seu pedaço de território".

Aliás, a crescente incerteza organizacional e a racionalidade limitada (i.e., o facto de os indivíduos terem limitações cognitivas que os impede de tomar decisões puramente racionais tendo por base a totalidade da informação) são apontados, por Bacharach e Lawler (1998), como os grandes factores responsáveis pela queda da organização racional e o advento da organização política. De acordo com Crozier e Friedberg (1977), não se trata apenas dos actores organizacionais terem limitações provenientes das imperfeições do conhecimento e da informação, mas sobretudo de um fenómeno ligado às representações e às capacidades cognitivas: cada um vê a organização sob o ângulo dos seus objectivos; cada actor tem um campo de competência particular e conhecimentos limitados por esse campo. Todos defendem o seu domínio, e todos o fazem tanto mais ardentemente quanto maiores forem as suas convicções na sua prática quotidiana e na sua lógica. 
Toffler (1991), ao projectar o seu olhar atento sobre o quadro da vida social e económica actual - com as devidas actualizações no seio organizacional - entende que depois de ultrapassada a lógica do homo economicus onde a riqueza era, por excelência, a base de poder, os tempos mais recentes afiguram-se de outra natureza. Cada vez mais, uma quantidade considerável de negócios emerge como sendo fruto de formação, da informação, do conhecimento e da criatividade, fazendo dos detentores do conhecimento os ímans do poder - aqueles de quem os outros e a própria organização dependem para decidir e prosperar. Importa destacar que a este nível, multiplicam-se os casos de organizações que utilizam o conhecimento para exercer o poder - daí a concomitante relevância que temas como a confiança, o envolvimento, o empenhamento e os comportamentos extra-papel têm vindo a assumir nas agendas dos líderes organizacionais. Quantos líderes não pretendem obter maior empenhamento dos seus colaboradores sem despenderem mais recursos financeiros? (REGO e CUNHA, 2004). Trata-se do intuito implícito de obter dos empregados níveis mais elevados de compromisso e empenho esforçado através de "símbolos mais baratos". Estamos perante um novo paradigma de gestão das organizações que equipara o poder ao conhecimento pretendendo obter, usando a terminologia de SCOTT (1992), mais leite de vacas contentes.

Embora prevaleçam alguns laivos de tabu - agravados pelo decréscimo de confiança nas instituições e continuadas revelações de corrupção e desaire político trazidas a lume pelos media - e subsistam os estudos de cariz especulativo, as duas últimas décadas testemunharam a redescoberta e o florescimento do estudo do poder e do comportamento político nas organizações - praticamente adormecido desde os trabalhos de Weber (1947). Este florescimento não está imune ao conjugar de alguns acontecimentos capitais, como é o caso da entrada nas organizações de cidadãos conscientes, atentos e socializados com a actividade política iniciada durante os movimentos dos protestos dos anos sessenta (FARRELL e PETERSEN, 1982) - e que em Portugal corresponde aos movimentos ocorridos após o 25 de Abril de 1974 (CABRALCARDOSO, 1996).

Por outro lado, esta evolução não se efectivaria se as ciências organizacionais não tivessem superado a velha lógica racionalista, sucedida por uma matriz interpretativa que acompanha a descoberta das culturas organizacionais, dos climas psicossociais, onde os mitos, as linguagens, os significados, os pressupostos básicos dão corpo e impõem-se como peça chave do conteúdo e da essência organizacional (FERRIS et al., 1984; CLEGG e HARDY, 1996).

De acordo com a perspectiva política, as organizações deixam de ser encaradas unicamente como um espaço de acção individual e colectiva decorrentes apenas da autoridade formal hierárquica cravada nas suas estruturas, para passarem a ser vistas como territórios pluralistas, compostos e subdivididos por subunidades explicadas na base de objectivos e estratégias corporizadas nos comportamentos estratégicos dos actores (BALDRIDGE, 1971; BACHARACH e LAWLER, 1980; NEVES e CARVALHO, 2002; AMMETER et al., 2002; 2004). A interface entre as diferentes subunidades pode ocasionar competição, disputa e conflito, como resultado de subculturas, valores, lideranças e interesses distintos. Desta forma, o conflito outrora visto como uma patologia organizacional, passa a ser perspectivado como um fenómeno endémico, construtivo, exercendo funções profiláticas no seio organizacional (LUCAS, 1987; EISENHARDT, KAHWAJY e BOURGEIOS III, 1997).

Assim sendo, esta concepção politizada das organizações vem pôr em causa a versão demasiado voluntarista e unificadora dos objectivos organizacionais - sinónimo pretenso de bem comum. Quer isto dizer que as organizações são percorridas por uma delicada teia de interesses, propósitos, interacções, negociações e compromissos entre os vários grupos internos (e externos), significando que quem tem objectivos são os indivíduos e não as organizações 
$($ FRIEDBERG, 1995) - estamos perante uma concepção activa do indivíduo no contexto do grupo. Aliás, a expressão celebrizada por Michel Crozier (1965) - actor organizacional traduz essa ideia na perfeição descrevendo um indivíduo no seio de um grupo, com objectivos, necessidades e anseios pessoais, cuja zona de acção concreta the confere trunfos para jogar o jogo do poder e da política.

Note-se que a perspectiva política não aparece nos estudos organizacionais como um substituto da visão racionalista, mas antes como seu complemento, pelo que as duas versões não devem ser consideradas como mutuamente exclusivas (TUSHMAN, 1977; MILES, 1980). Conforme defendido e demonstrado empiricamente por Cabral-Cardoso (1995), os indivíduos que utilizam instrumentalmente técnicas e modelos matemáticos acreditam que isso constitui o modo "racional" de tomar decisões, sendo levados a procurar convencer os outros intervenientes da superioridade da sua argumentação. A sua utilização intencionalmente política só será eficaz se dela transparecer uma imagem de racionalidade e consistência, aumentando a possibilidade de que os resultados influenciem, de facto, a decisão final.

\section{Conclusão}

Não obstante hoje se torne objecto de grande aceitação a ideia de que as organizações são percorridas por uma delicada teia de interesses e de que são per se palcos abertos e permeáveis ao exercício do poder e da actividade política, o tema não tem concitado interesse e entusiasmo generalizado.

Apesar dos avanços registados nos últimos anos, permanecem por explorar e "colorir" inúmeras áreas cinzentas, havendo, por isso, um grande espaço de progressão. Trata-se, com efeito, de uma das áreas de mais difícil investigação devido à sua enorme sensibilidade e complexa conceptualização e operacionalização. Subjacente ao estudo do poder e da política nas organizações está (e estará?) associada a crença e o tabu de que a sua manifestação se espartilha num conjunto de comportamentos socialmente reprováveis, manobras e acordos efectuados na "penumbra" dos bastidores que servem apenas para colmatar os interesses de uma pequena minoria e de que o seu impacto, a existir, só poderá ser negativo e altamente pernicioso para os indivíduos e para a organização.

Embora admitindo o largo espectro disfuncional de algumas das manobras, tácticas e comportamentos políticos que alguns actores manifestam em cenários de trabalho (há, de facto, quem siga à risca o lema "no amor e na guerra vale tudo") e embora frisemos que tais práticas são ética e moralmente repugnantes podendo atingir "níveis requintados de maquiavelismo (CABRAL-CARDOSO, 1996, p. 404), seria absolutamente naive, irrealista e imprudente rejeitálas em bloco.

A actividade política é uma inevitabilidade das organizações. Conforme MANGHAM (1979, p. 17) gizou:

quando existe um espaço de escolha acerca da direcção de uma [...] organização complexa, pessoas razoáveis irão discordar acerca dos meios e dos fins, e pessoas razoáveis irão, igualmente, lutar (figurativamente falando) por aquilo que acreditam ser o curso certo de acção. Muitas das decisões organizacionais significativas são o resultado de um processo político e social.

\footnotetext{
${ }^{4}$ Para Friedberg (1993, p. 69), deparamo-nos com uma visão muito mais abstracta, complexa, e menos cooperante da organização. Nas suas palavras, "a organização desencarnou-se, agora já não tem mais do que um contexto de acção no qual se atam e se geram relaçoes de cooperação, de trocas e de conflitos entre actores com interesses divergentes".
} 
Quer isto dizer que a fluidez, a imprevisibilidade e a elevada velocidade do contexto organizacional abriu um largo caminho aos jogos de poder e à movimentação política, significando que quem não seja politicamente habilidoso (FERRIS et al., 2000) ou que se recuse a jogar o jogo do poder e da política irremediavelmente, fracassará. Para Buchanan e Badham (1999) esta perda de inocência é crucial já que aqueles que insistirem que o comportamento político é, invariavelmente, prejudicial e deve ser erradicado não conseguirão progredir em cenários de trabalho; ou então, aqueles que crêem que o envolvimento na trama política é pouco razoável, tornarão a experiência de liderar absurdamente frustrante, colhendo apenas o descontentamento, o cinismo, a insatisfação e o desinvestimento dos seus colaboradores e, por conseguinte, comprometerão os resultados organizacionais.

Há poder e política envolvido nas organizações e a menos que queiramos assumir o papel de avestruz todos, sem excepção, somos jogadores e todos, inevitavelmente, "estamos expostos ao processo de dar e receber" (APPELBAUM e HUGHES, 1998, p. 86)!

\section{Referências}

AMMETER, P. A. et al. Toward a political theory of leadership. The Leadership Quarterly, v. 13, p. 751-796, 2002.

AMMETER, P. A. et al. Editorial: introduction to the leadership quarterly special issue on political perspectives in leadership. The Leadership Quarterly, v. 15, p. 433-435, 2004.

ALLEN, R. W. et al. Organizational politics: tactics and characteristics of its actors. California Management Review, v. XXII, n.1, p. 77-83, 1979.

ALVESSON, M. Questioning rationality and ideology: on critical organisation theory. International Studies of Management and Organizations, v.14, p. 61-79, 1984.

APPELBAUM, S. H.; HUGHES, B. Ingratiation as a political tactic: effects within the organization. Management Decision, v. 36, n. 2, p. 85-98, 1998.

BADER, G. Good guys finish last: understanding organizational politics. Health Care Supervisor, v.10, n. 1, p. 23-26, 1991.
BACHARACH, S. B.; LAWLER, E. J. Power and politics in organisations: the social psychology of conflict, coalitions, and bargaining. San Francisco: Jossey Bass, 1980. Political alignments in organizations: contextualization, mobilization and coordination. In: KRAMER, R. M.; NEALE, M. A. (Eds.). Power and influence in organizations. California: Sage, 1998. p. 67-88.

BALDRIDGE, J. V. Power and conflict in the university. New York: John Wiley, 1971.

BRADSHAW-CAMBALL, P.; MURRAY, V. V. Ilusions and other games: a trifocal view of organizational politics. Organization Science, v.2, p. 379-398, 1991.

BUCHANAN, D. A.; BADHAM, R.. Power, politics and organization change: winning the turf game. London: Sage, 1999.

BUGENTAL, D. B.; LIN, E. K. The many faces of power: tThe strange case of dr. Jekyll and Mr. Hyde. In: LEE-CHAI, A. Y.; BARGH, J. A. 
(Eds.). The use and abuse of power: multiple perspectives on the causes of corruption. Philadelphia: Psychology, 2001. p. 115-131.

BURNS, T. Micropolitics: mechanisms of institutional change. Administrative Science Quarterly, v. 6, n. 3, p. 257-281, 1961.

CABRAL-CARDOSO, C. A utilização simbólica e política de informação técnica: estudo de processos de decisão em I\&D. Comportamento Organizacional e Gestão, v. 1, n. 1, p. 77-90, 1995.

. O factor político nas organizações.

In: MARQUES, C. A.; CUNHA, M. P. (Eds.). Comportamento organizacional e gestão de empresas. Lisboa: D. Quixote, 1996. p.397-419.

CAVANAGH, G. F.; MOBERG, D. J.;

VELASQUEZ, M. The ethics of organizational politics. The Academy of Management Review, v. 6, n.3, p. 363-374, 1981.

CROZIER, M. Le phénomène bureaucratique. Paris: Éditions du Seuil, 1965.

.. The problem of power. Social

Research, 40, p. 211-218, 1973.

CROZIER, M.; FRIEDBERG, E. L'acteur et le système. Paris: Éditions du Seuil, 1977.

CUNHA, M. P. et al. Manual de comportamento organizacional e gestão. Lisboa: RH, 2003.

CYERT, R; MARCH, J. G. A behavioural theory of the firm. Englewood Cliffs, New Jersey: Prentice Hall, 1963.

DRORY, A.; ROMM, T. The definition of organizational politics: A review. Human Relations, v. 43, n.11, p. 1133-1154, 1990.

EISENHARDT, K, M.; BOURGEOIS III, L. J. Politics of strategic decision making in high velocity environments: Toward a midrange theory. The Academy of Management Journal, v. 31, n. 4, p. 737-770, 1988.

EISENHARDT, K. M.; KAHWAJY, J. L.; BOURGEIOS III, L. J. How management teams can have a good fight. Harvard Business Review, v. 75, n. 4, p. 77-85, 1997.
FARREL, D.; PETERSON, J. C. Patterns of political behavior in organizations. Academy of Management Review, v. 7, n. 3, p. 403-412, 1982.

FERRIS, G. et al. Myths and politics in organizational contexts. Group and Organization Studies, v. 14, n.1, p. 83-103, 1984.

FERRIS, G.; FEDOR, D.; KING, T. A political conceptualization of managerial behavior. Human Resource Management Review, v. 4, p. 1-34, 1994.

FERRIS, G.; PERREWÉ, P.L.; ANTHONY, W. P.; GILMORE, D. C. Political skill at work. Organizational Dynamics, 28, 25-37, 2000.

FRENCH, W. L; BELL JR, C. H. Organizational development: behavioral science for organization improvement. 4th ed. NJ: PrenticeHall, 2000.

FRIEDBERG, E. O poder e a regra: dinâmicas da acção organizada. Lisboa: Instituto Piaget, 1995.

GANDZ, J.; MURRAY, V. V. The experience of workplace politics. Academy of Management of Journal, n. 23, p. 237-251, 1980.

GARDNER, W. On leadership. New York: Free Press, 1990.

GIOIA, D. A.; LONGNECKER, C. O. Delving in the dark side: The politics of executive appraisal. Organizational Dynamics, v. 22, n.3, p. 47-58, 1994.

HARDY, C. Power and politics in organizations. Cambridge: University Press, 1995.

HARDY, C.; CLEGG, S. R. Some dare call it power. In: CLEGG, S. R.; HARDY, C.; NORD, W. R. (Eds.). Handbook of organizations studies. London: Sage, 1996. p. 622-641.

KANTER, R. M. Power failures in management circuits. Harvard Business Review, v. 57, n. 4, p. 65-75, 1979.

LUCAS, R. Political-cultural analysis of organizations. Academy of Management Review, v. 12, n.1, p. 144-156, 1987. 
MANGHAM, I. The politics of organizational change. CT: Greenwood, 1979.

MARCH, J. G. The power of power. In: EASTON, D. (Ed.). Varieties of political theory. New Jersey: Prentice-Hall, 1966, p. 39-70.

$M A R C H$, J. G.; SIMON, H. A. Organizations. New York: Wiley, 1958.

March, J. G.; Simon, H. A. Organizations revisited. Industrial and Corporate Change, v. 2, p. 299-316, 1993.

MAYES, B. T.; ALLEN, R. W. Toward a definition of organizational politics. Academy of Management Review, v. 2, p. 672-678, 1977. MADISON, D. et al. Organizational politics an exploration of manager's perceptions. Human Relations, v. 33, p. 70-100, 1980.

MILES, R. H. Macro organizational behaviour. California: Goodyear, 1980.

MINTZBERG, H. Power in and around organizations. Englewood Cliffs, NJ: Prentice Hall, 1983.

MORGAN, G. Images of Organization. London: Sage, 1996.

MUMBY, D. K. Power and politics. In: JABLIN, F. M.; PUTNAM, L. L. (Eds.). The new handbook of organizational communication: advances in theory, research, and methods. California: Sage, 2000. p. 585-623.

NARAYANAN, V. K.; FAHEY, L. The micropolitics of strategic formulation. Academy of Management Review, v.7, n.1, p. 25-34, 1982.

NEVES, J.; CARVALHO J. M. Poder, conflito e negociação. In: CARVALHO, J. M.; NEVES, J.; CAETANO, A. (Eds.). Manual de psicologia das organizações. Lisboa: McGraw-Hill, 2002. p. 501-529.

NORD, W. R. Dreams of humanization and the realities of power. Academy of Management Review, v. 3, p. 674-679, 1978.

PATCHEN, M. The locus and bases of influence in organization decisions. Organization

Behavior and Human Performance, v. 11, p. 195-221, 1974.
PEABODY, R. L. Perceptions of organizational authority: a comparative analysis. Administrative Science Quarterly, v. 6, n. 4, p. 463-482, 1962. PFEFFER, J. Power in organizations. New York: Harper Collins, 1981.

PFEFFER, J. Gerir com poder: políticas e influências nas organizações. Venda Nova: Bertrand, 1992.

PETTIGREW, A. M. The politics of organizational decision-making. London: Tavistock, 1973.

PORTER, L. W.; ALLEN, R. W.; ANGLE, H. L. In the politics of upward influence in organizations. In: ALLEN, R. W.; PORTER, L. W. (Eds.).

Organizational influence processes. Glenview: Scott, Foresman and Company, 1983. p. 408422.

REGO, A.; CUNHA, M. P. Comportamento organizacional: XXI temas e debates para o séc. XXI. Comportamento Organizacional e Gestão, v. 10, n.1, p. 5-41, 2004.

ROBERTS, N. C. Organizational power styles: colective and competitive power under varying organizational conditions. Journal of Applied Behavioral Science, v. 22, n.4, p. 443-458, 1986.

SARAMAGO, J. Entrevista dada à BBC Brasil. Disponível em: < http.www.brazzilbriefing. com>. Acesso em: 22 out. 2004.

SCOTT, W. R. Organizations: rational, natural, and open systems. Englewood Cliffs, New Jersey: Prentice- Hall, 1992.

TOFFLER, A. Os novos poderes. Lisboa: Livros do Brasil, 1991.

WEBER, M. The theory of social and economic organizations. New York: Free Press, 1947. 